\title{
A visão psicanalítica da Identificação do Negro no Brasil: sua relação com a paranoia social
}

\author{
João Ezequiel Grecco' (iD) \\ Universidade São Paulo - USP
}

Christian Ingo Lenz Dunker ${ }^{2}$ (D)

Universidade São Paulo - Instituto de Psicologia Clínica

Artigos livres | Free articles | Articulos libres

DOI do artigo: 10.22481/odeere.v6i2.9692

RESUMO

Este artigo tem por objetivo a investigação dos impasses no processo da identificação do Negro no Brasil e seu transcurso sócio-histórico, moldado por fatores de uma paranoia social isso, implicada no processo de violência e crime. A psicanálise freudiana reconhece que a identificação é a primeva e primordial forma de ligação afetiva a um objeto, isto é, um processo profundamente enraizado na singularidade do sujeito e em nossas atividades sociais; por outro lado, na clínica psicanalítica haveria o testemunho dessa manifestação sintomática no processo da identificação. Palavras chave: Negro no Brasil, identificação, psiquiatria, patologias sociais, psicanálise.

\section{The psychoanalytic view of the identification of the Negro in Brazil: its relationship with the factors of social paranoia \\ ABSTRACT}

This article aims to investigate the impasses in the process of identifying Negroes in Brazil and their socio-historical development, shaped by factors of a social paranoia, which is implicated in the process of violence and crime. Freudian psychoanalysis recognizes that identification is the primeval and primordial form of affective connection to an object, that is, a process deeply rooted in the subject's uniqueness and in our social activities; on the other hand, in the psychoanalytic clinic there would be a testimony of this symptomatic manifestation in the identificatives process.

Keywords: Negro in Brazil, identification, psychiatry, social pathologies, psychoanalysis.

\section{La visión psicoanalítica de la identificación del negro en Brasil: su relación con los factores de la paranoia social RESUMEN}

Este artículo tiene como objetivo investigar los impasses en el proceso de identificación del negro en Brasil y su curso socio-histórico, conformado por factores de paranoia social, implicados en el proceso de violencia y crimen. El psicoanálisis freudiano reconoce que la identificación es la forma primordial y primordial del apego afectivo a un objeto, es decir, un proceso profundamente arraigado en la singularidad del sujeto y en nuestras actividades sociales; por otro lado, en la clínica psicoanalítica habría testimonio de esta manifestación sintomática en el proceso de identificación. Palabras clave: Negro en Brasil, identificación, psiquiatría, patologías sociales, psicoanálisis.

\section{Submetido em: 06/09/2021 | Aceito em: 03/11/2021}

\footnotetext{
1 Psicanalista. Professor e supervisor clínico no Centro Universitário de Santo André na faculdade de Psicologia e de enfermagem, professor visitante e supervisor da residencia medica e psiquiatria da Faculdade de Medicina do $A B C$ e do Centro de Estudos Psicanalítico (CEP). Pós Doutorando Instituto de Psicologia da USP sob a orientação do prof. Dr. Christian Ingo Dunker. Participante do LATESFIP (Laboratório de Teoria Social, Filosofia e Psicanálise - USP). Doutor em Psicologia social e mestre em Psicologia clínica (bolsista CAPES) pela PUCSP. Especialista em Psicoterapia do adolescente e do adulto pelo Instituto Sedes Sapientiae. E-mail: jegrecco@usp.br

2 Psicanalista, Professor Titular do Instituto de Psicologia da USP (2014) junto ao Departamento de Psicologia Clínica. Obteve o título de Livre Docente em Psicologia Clínica (2006) após realizar seu Pós-Doutorado na Manchester Metropolitan University (2003). Possui graduação em Psicologia (1989), mestrado em Psicologia Experimental (1991) e doutorado em Psicologia Experimental (1996) pela Universidade de São Paulo. Atualmente é Analista Membro de Escola (A.M.E.) do Fórum do Campo Lacaniano. E-mail: chrisdunker@usp.br
} 
Portanto, o que conheciam disso no plano do etnógrafo era mais ou menos como no do jornalismo, mas seus inconscientes funcionavam segundo as boas regras do Édipo. Era o inconsciente que tinham vendido a eles ao mesmo tempo em que as leis da colonização, forma exótica, regressiva, do discurso do mestre, frente ao capitalismo que se chama imperialismos. (LACAN, 1969-1970, p.85).

O mundo colonial é dividido em compartimentos. Sem dúvida é supérfluo, no plano da descrição, lembrar a existência de cidades indígenas e cidades europeias, de escolas para indígenas e escolas para europeu, como é supérfluo lembrar o apartheid na África do Sul. Entretanto, se penetrarmos na intimidade desta divisão, obteremos pelo menos o benefício de pôr em evidência algumas linhas de força que ela comporta. Este enfoque do mundo colonial, de seu arranjo, de sua configuração geográfica, vai permitir-nos delinear as arestas a partir das quais se há de reorganizar a sociedade descolonizada. (FANON, 1968, pp.27-28).

Uma civilização que se mostra incapaz de resolver os problemas que seu funcionamento provoca é uma civilização decadente. Uma civilização que opta por fechar os olhos para seus problemas mais cruciais é uma civilização doente. Uma civilização que se esquiva diante de seus princípios é uma civilização moribunda. O fato é que a chamada civilização "europeia", civilização "ocidental", tal como foi moldada por dois séculos de governo burguês, é incapaz de resolver os dois principais problemas aos quais sua existência deu origem: o problema do proletariado e o problema colonial. Levada ao tribunal da "razão" e ao tribunal da "consciência", a Europa se mostra impotente para justificar-se. Cada vez mais, se refugia na hipocrisia, tanto mais odiosa por ter cada vez menos chance de enganar. A Europa é indefensável. (CÉSAIRE, 2020, p.9) 


\section{A dinâmica da escravatura no Brasil e suas consequências contemporâneas}

A fim de compreendermos as relações dinâmicas da escravatura no Brasil e suas consequências antes e após o ato da lei da libertação, torna-se necessário entendermos a ideia da corrente do pensamento antropológico, entre o evolucionismo cultural e o particularismo histórico, desde meados do século XIX até a década de 1930, o que coincide com a análise de Arthur Ramos a respeito da paranoia do Negro no viés da miscigenação e da degenerescência.

Se a teoria do evolucionismo cultural esteve impregnada do conceito da hereditariedade e da moral, entre meados do século XIX até o início do século XX essa teoria se constatava na dimensão das relações entre colonizadores e colonizados. Por outro lado, o conhecimento dos aspectos das sociabilidades de determinados grupos colonizados, nos quais crenças e estilos de vida tornaram-se de fundamental importância para o êxito de exploração praticada por colonizadores em territórios estranhos, estabelece as relações de poder sobre o outro.

Os evolucionistas (Spencer, Taylor e Morgan) baseavam-se na noção de que as sociedades não europeias poderiam ser configuradas como grupos inferiores na escala social. Esses grupos poderiam evoluir, mas ao longo de muito tempo, e com isso haveria um desdobramento na teoria evolucionista clássica (tomada pela análise de Morgan) na compreensão do pensamento cultural da época, ou seja, considerar a unidade psíquica do homem e a ideia de sobrevivência.

No Brasil isso ocorreu na exploração da mão de obra escrava do índio e do Negro, desta maneira não se acreditava na desigualdade psíquica entre indivíduos e entre grupos, mas sim em uma unidade. Por outro lado, o sentido de sobrevivência emoldura em objetivar e explicar certas tradições antigas e de difícil compreensão para sociedades consideradas mais desenvolvidas, visto que permaneciam em grupos sociais mais evoluídos e asseguravam de certa maneira a evolução cultural do elo com o passado, sendo que os requisitos indicariam a trajetória das sociedades na linha evolutiva.

Inaugurou-se, então, uma metodologia de análise segundo a qual o conteúdo comparativo busca características semelhantes de diversas sociedades, comparando-as com a sociedade europeia, ou seja, em que medida e nível na 
escala evolutiva civilizatória o outro se situaria na relação enquanto grupo social. Assim, ao adotar esse viés, o método comparativo se baseava numa história unilinear, na qual fenômenos semelhantes ocorreriam no mundo em razão de causas semelhantes, desconsiderando os processos históricos internos de cada sociedade e até mesmo ignorando as causas dessa sociedade. Esse é o motivo pelo qual, no Brasil, o índio, tratado como "coisa", não comungava a eucaristia cristã implantada pela ação da exploração portuguesa e sua cultura não possuía peso, sendo por isso tomado como escravo; o Negro, por sua vez, mostrava-se como estrangeiro, já vinha escravo das colônias da África ou feito escravo nas lutas tribais que viam na escravidão um meio de comércio.

Para que o método de investigação se mostrasse consistente consideravamse as descrições de viajantes, missionários e jesuítas - no Brasil houve, nesse caso, uma enorme expansão com a Companhia de Jesus - a respeito das regiões e sociedades nas quais estavam interessados. De fato, há um problema nessa forma de análise: a credibilidade, que se baseava na similitude dos fatos relatados dada pela impossibilidade de os narradores saberem o que era descrito entre eles, em virtude das razões geográficas.

Assim, as sociedades não europeias, consideradas selvagens, poderiam ser parâmetro ao entendimento do funcionamento da sociedade em seu princípio, ainda que os evolucionistas imaginassem que os selvagens contemporâneos seriam semelhantes aos primeiros homens, aqueles eram representados como o mais próximo que se poderia chegar de uma compreensão sobre o assunto (SOILO, 2014).

Nessa análise em que os evolucionistas abordam tal conceito de selvagens, haveria o contraponto com a sociedade europeia. A isso convém destacar a proposta de Lewis Morgan em seu livro Systems of Consanguinity and Affinity of the Family, publicado em 1871, no qual há referências de parentesco a influenciar as relações nos grupos sociais, as relações de ocupação do solo e as relações de propriedade. Dessa maneira, faceia o entendimento das relações sociais humanas como unilinear, nas quais toda a sociedade estaria fadada a passar pelas mesmas etapas do desenvolvimento e com isso poder-se-ia enfatizar a noção de que a sociedade dita humana passaria pelas seguintes etapas: selvageria, barbárie e civilização. A selvageria antecederia a barbárie e, por fim, a civilização de modo 
natural e inexorável. Os estágios se relacionariam entre si a partir da ideia do progresso inevitável cujo parâmetro consistiria no modo de vida europeu da época (SOILO, 2014).

No Brasil, a dinâmica da escravidão se serviu da visão evolucionista como um elemento a substantivar e justificar a escravatura. Para as cortes de Portugal, as experiências em Angola e Moçambique legitimaram sua implantação na monocultura da cana-de-açúcar e, dessa maneira, foi dado ao Negro um estatuto de desterro, sem lugar, sem identidade, sem retorno à origem, cujas condições resultam na implantação, sem resistência, da exploração da mão de obra escravocrata. Para esse fim, houve uma intensa relação com o tráfico negreiro transatlântico no período, o que suscitou padrões de alforria e oportunidades de resistências escravas coletivas, nas quais almejavam alçar a liberdade, fruto de uma sistemática de força e poder em desordem na ocasião.

Se a tônica do sistema escravista brasileiro se deu na estreita relação entre o tráfico transatlântico escravocratas (bastante volumoso) e o número constante de alforrias, essa lógica possibilitou aumentar a intensidade do tráfico sem comprometer a ordem social escravista. Assim, as revoltas dos escravos foram sufocadas sem nenhum termo de negociação por parte das autoridades coloniais portuguesas, com a garantia de continuidade da escravatura. De fato, as revoltas foram coletivas, o que representou a forma mais radical de contestação da escravidão, sem, todavia, que toda revolta almejasse destruição do regime escravocrata. Muitas buscavam apenas corrigir o excesso de tirania senhorial, diminuindo a um limite tolerável a reconquista de ganhos perdidos ou punindo feitores e senhores particularmente tirânicos (REIS apud SCHWARCZ; GOMES, 2018).

Portanto, as condições expostas até aqui sustentam a dinâmica da escravatura: a mão de obra necessária no Brasil colonial. Diante disso ousaríamos afirmar a coexistência de um regime escravocrata e de um sistema capitalista. Nesse sentido, abrimos breve discussão, visto que nosso tema considera a condição do Negro e as anomalias psíquicas postas como signatárias da miscigenação e da degenerescência apontadas no Negro, no qual o crime e a punição estariam na ordem determinista de um sistema capitalista, que, por sua vez, não promoveu laços sociais, pois no período do Brasil Colônia o Negro não possuía nada (salário e poder de consumo) a não ser sua força de trabalho. 
Além disso, no Brasil não houve uma revolução burguesa. O país consolidouse capitalista desde os tempos coloniais, mas o sistema capitalista necessita de uma economia na qual se estabeleça uma demanda interna de consumidores, sendo tais consumidores elementos de um meio de produção no qual haja condição de trabalho livre e assalariado. Para as condições brasileiras, isso ocorreu com a entrada de mão de obra imigrante, que substituiu o escravo negro nas fazendas de café, passando o imigrante a corresponder à máxima do capital: assalariado e consumidor, fatores fundamentais para o desenvolvimento do capitalismo.

Há dois momentos que de certa maneira contribuíram para a formação do capitalismo no Brasil: a independência do Brasil como um marco histórico em que o país deixa de lado a condição da era colonial e a formação de uma sociedade nacional; e a substituição da mão de obra escrava pela do imigrante assalariado, o que propiciou a dimensão de um sistema capitalista que perdura até a contemporaneidade.

Se o trabalho escravocrata se tornou necessário para a colônia, pelo fato de não haver mão de obra suficiente nem na colônia nem na metrópole, esse fato representou lugar-comum nas colônias portuguesas e espanholas, pois a utilização de mão de obra branca não se mostrou, a princípio, ponto a ser levado a sério. Tanto os povos indígenas na construção dos engenhos de açúcar quanto o Negro na lavoura de café forneceram à colônia a dimensão que a corte de Portugal almejava: a exploração natural de uma monocultura e uma mão de obra que servia a seus interesses.

Portanto, com desenvolvimento de uma monocultura (a cana-de-açúcar), sua crescente demanda na produção e a ausência de mão de obra livre, a utilização do trabalho escravocrata atendeu as necessidades do momento. Fato que atrelava a produção brasileira aos centros europeus consumidores que aumentavam a demanda como também intensificavam o tráfico escravo. Ora, se a condição do capitalismo reside na "exploração" do trabalho assalariado pelo capital, como essa condição não existia no Brasil Colônia, logo, não haveria o capitalismo no Brasil Colônia. Não necessariamente.

O fato é que a mão de obra escravocrata, explorada pelo capital, gerava e aumentava os lucros, características que determinaram o tipo de exploração 
agrária, ou seja, uma monocultura lucrativa a atender um mercado externo (PRADO JUNIOR, 1980). O que se constata é, sim, um trabalho livre e assalariado, raro que fosse, mas vinculado aos mestres-do-açúcar e à parte de uma elite na administração do tráfico escravo.

Por fim, essa dinâmica escravocrata se decompôs por tantas alforrias, nas quais o Negro conseguia a condição de "estar livre", porém sem sair do Brasil e tampouco tornar-se alguém diferente, a não ser adquirir um pedaço de terra e também alguns escravos 3 .

Assim, em 1850, com a lei que proibia o tráfico de escravos, não tardaria a Abolição. Em 1888, finalmente abolia-se a mão de obra escrava e instaurava-se o regime de trabalho livre. Houve, para o Negro, sua devida libertação; no entanto, haveria outra escravatura, agora pelo poder de vigilância e castigo, visto que ele não possuía aptidões a não ser desempenhar a função de escravo. Nessa condição, o Negro encontrava-se despreparado para competir com os imigrantes que detinham a técnica agrícola, se organizavam em grupos e, além disso, eram letrados, poucos, mas letrados.

Nessa nova sociedade burguesa a despontar (não só por meio da cana-deaçúcar, mas também do café), os primórdios de um desenvolvimento industrial, a estratificação das classes (por profissão, saber, cor, miscigenação) e o conceito da degenerescência (ainda fortemente influenciado pelos países "desenvolvidos" europeus) constituirão um dos tópicos a nortear de certa forma a higienização a ser levada a cabo na sociedade brasileira após a escravatura; além da influência determinante da ciência médica europeia - que estabelecia na degenerescência e na miscigenação fundamentos antecipatórios ou justificáveis para o crime e a punição -, segundo a qual a hereditariedade e as relações familiares legitimavam esse dispositivo.

\section{Conceito histórico do pensamento escravocrata e a psiquiatria na figura do degenerado e miscigenado}

No Brasil, a miscigenação mostra-se implícita desde a chegada dos europeus

\footnotetext{
${ }^{3}$ A lei do Ventre Livre, de 1871, contempla os jovens nascidos após essa data e maiores de 21 anos para sua total liberdade.
} 
e suas relações com o Índio, e posteriormente com o Negro. Outro fator dessa lógica binária apresenta-se na história da degenerescência e suas relações com a hereditariedade e a moral, o que, de certa maneira, apontaria de forma estigmatizada a relação do Negro com o crime e a punição.

A publicação, em 1857, do Traité des Dégénérescences, de BenedictAugustin Morel, revela que a teoria da hereditariedade dos transtornos mentais estabelece uma relação com a proposição religiosa católica, segundo a qual o homem teria sido criado, na perfeição, por Deus. Desse modo, a degeneração seria correlata ao pecado original, assim constituindo a transmissão para a descendência de taras, vícios (álcool, jogo, prostituição etc.) e traços da morbidez adquiridos pelos antecessores, que, conforme passassem de geração a geração, tenderiam à completa desnaturação dessa linhagem (PEREIRA, 2008).

No Brasil, na relação da colonização, tanto o Índio como o Negro sofreram um longo processo de catequese, entendida então como a conversão dos gentios, dos que não possuíam alma, sem pecado original. Isso possibilitou atribuir a essas culturas que advogam crenças outras, no caso do catolicismo, condições da hereditariedade biológica e moral. E, correlato a isso, a noção de que haveria um fator biológico de natureza hereditária estabelecia uma contingência relevante na etiologia dos transtornos mentais, o que se constata desde os primórdios da psiquiatria contemporânea.

Os elementos hereditários compõem a ideia de que haveria predisposição a esses fatores perturbadores, sendo que o Negro estaria na condição desse estigma determinante e, além disso, fora dos preceitos da moral. Pinel destaca de forma significativa esses fatores em seu Traité médico-philosphique sur l'aliénation mentale, de 1801, influenciando outros autores nessa mesma linha de pensamento, como Jean-Étienne Esquirol e Jean-Pierre Falret. Com isso, as predisposições às perturbações morais e à loucura assumiam uma perspectiva de traços transmitidos por gerações familiares. Nesse caso, o Negro estaria a responder a todo tipo de implicância dimensionada pela hereditariedade ou pela moral.

Morel esforçou-se significativamente na tentativa de uma nosografia psiquiátrica fundada na concepção da etiologia natural dos transtornos mentais, buscando uma unidade entre o quadro clínico, os aspectos da evolução e a causa biológica de cada entidade diagnosticada. Mas existiam algumas questões que 
esbarravam em formulações deterministas e pragmáticas, visto que as ideias morelianas apontavam na direção das degenerescências, às quais se vinculavam a pluralidade, isto é, repousam na concepção de que a herança transmitida através das gerações não se restringia somente ao plano biológico, mas também às dimensões morais e do comportamento, sejam virtuosos ou viciados. Entre as características atribuídas ao Negro por causa de sua condição miscigenada, temos, por exemplo, a afirmação de que não serve para nada, apenas para ser serviçal, pois sua constituição moral apresenta-se degenerada e por isso ele não reconhece as etiquetas da sociedade.

A degenerescência, sob a ótica de Morel, suporta várias condições causais (e que se associam à noção de uma posição paranoica em relação ao Negro), entre as quais podemos destacar: o alcoolismo, a alimentação deficiente e diferente, o meio social miserável, e não poderíamos excluir as relações de parentescos familiares, em particular, o infante.

A pluralidade a que nos referimos, isto é, a ênfase segundo a qual as condições hereditárias assumiriam papel relevante, não só nos complexos familiares, mas sem dúvida nas condições da criança, que, por sua vez, encarnaria a anormalidade (FREUD, [1893-1899] 2006), possui a mais árdua intenção em estabelecer as condições da influência dos aspectos hereditários.

A condição na qual a patologia nervosa deve ser vista sob a ótica da hereditariedade assenta-se na condição da hereditariedade similar, em que os aspectos hereditários possuem em si fator primordial, a exemplo da miopia, da síndrome de Down etc. Por outro lado, a hereditariedade dissimilar, que seria mais relevante que a outra, deixa lacunas que deveriam ser satisfeitas antes que se pudesse chegar a uma solução satisfatória dos problemas etiológicos.

Nessa perspectiva, a hereditariedade dissimilar aponta que os membros de uma mesma constelação familiar podem ser afetados pelos mais diversos distúrbios nervosos, funcionais e orgânicos - aliás, sem que se possa constatar qualquer lei que determine a substituição de uma doença por outra ou de sua sucessão entre gerações. O que se constata é que nesses complexos familiares haveria membros saudáveis. Ora, a teoria da hereditariedade dissimilar não nos diz porque uma pessoa tolera a mesma carga hereditária sem sucumbir a ela, ou porque outra pessoa, doente, é acometida por uma afecção nervosa específica, dentre todas 
as doenças que compõem a grande família das doenças nervosas, em vez de outra: a histeria no lugar da epilepsia ou a psicose no lugar de algo qualquer (FREUD, [1893-1988] 2006).

A posição freudiana nesse sentido mostra que as condições dos fatores hereditários na análise e no diagnóstico das doenças nervosas exerceram enorme influência na tentativa de Arthur Ramos em desvincular a hereditariedade e a degenerescência do Negro no Brasil. Por outro lado, constatamos em Freud o esforço de separação, nesse sentido, ao lançar mão de uma inovação nosográfica, dispondo lado a lado a histeria e a neurose obsessiva, como distúrbio autossuficiente e independente, constatando que a maioria das autoridades situava as obsessões entre as síndromes constitucionais da degenerescência mental ou entre as condutas como a neurastenia (FREUD, [1983-1988] 2006).

Se os complexos familiares se condicionavam sob o julgo de anormalidades, independentemente sob quais tipos se apresentassem, as crianças (frutos dessas anomalias) talvez pudessem ser confinadas em asilos ou reformatórios. No Brasil, e em particular com o Negro após a escravatura, esse recurso não só antecipava atos transgressivos como também justificava o que a degenerescência sedimentava, ou seja, que as crianças mais ou menos débeis do ponto de vista intelectual sofriam de perversões dos instintos: ladrões, mentirosos, homossexuais, homicidas etc. (FOUCAULT, 1972).

O poder da psiquiatria não se restringiu apenas ao saber. Ultrapassou muito além disso e, na contemporaneidade, não se faz de outra maneira, visto tudo o que se avalia como anormal em relação à disciplina escolar, militar, familiar etc. Será reivindicado pela psiquiatria como a condição de fazer ortopedia no malestar do sujeito.

Portanto, a noção de degenerescência e todas as consequências que se possam atribuir como anormalidade encontravam na criança a anomalia produzida pelos pais. E, por outro lado, a criança degenerada consiste numa criança anormal, cuja anomalia é tal que pode produzir, em certo número de circunstâncias determinadas e após certo número de acidentes, a loucura.

Dessa maneira, a degenerescência configuraria a predisposição para lançar mão do conceito de anomalia. Na criança tornar-se-á possível a loucura do adulto e, além disso, demarcará os complexos familiares. Tomados em bloco e sem 
definição bem estrita, a criança fará desse duplo fenômeno - a anomalia e a loucura - o suporte coletivo que é a família (FOUCAUT, 2006).

$\mathrm{Na}$ análise do Negro e de suas condições sociais após a escravatura, os fatores da degenerescência, associados à noção da miscigenação, estabeleceram como sentido que as anormalidades apontavam para uma coletividade, que agora deveria se inserir no complexo social. Todavia, esta não tinha construído um percurso histórico e tampouco contribuíra para as relações sociais. Ou seja, o Negro, ao deixar de ser "coisa" escravo passa a ser anônimo, não possui função social a não ser fazer o que sempre fez, "servir" para qualquer coisa.

Haveria um peso nisso tudo ou pelo fator da hereditariedade implicada nos complexos familiares, como já salientamos, ou nos imperativos morais, visto que sobre o Negro pairava em sua dimensão uma ideia paranoica de que a sociedade deveria estar prevenida, porque ele mostrava-se inconsistente, anormal, sem cultura e alheio aos costumes sociais que valorizava ou que se esperava que o fizesse. A todos esses fatores, que a psiquiatria tomará em seu poder, Arthur Ramos dará outro fundamento e configuração ao convocar a psicanálise e a psicologia social na análise das condições do Negro e de sua estigmatização - a condição paranoica da degenerescência e da miscigenação - que pudesse desvincular o crime e a punição.

\section{As contribuições de Arthur Ramos na compreensão do Negro pela via da etnia e dos conceitos psicanalíticos}

Arthur Ramos (1903-1949) foi um médico alagoano que se destacou em várias esferas do saber, entre elas a Psicanálise, a Criminologia, o Folclore, a Antropologia e a Psicologia Social. Dentre esses percursos aos quais se filiou analisemos a psicanálise a partir da qual Arthur Ramos fez suas primeiras e intensas articulações.

As ideias da psicanálise aportaram no Brasil em meados do século XX e, com isso, o estudo e a difusão de seus conceitos abrangeram um número significativo de psiquiatras e artistas, em particular aqueles engajados ao Movimento Modernista, do qual derivou a Semana Modernista, em 1922. No entanto, há uma 
ressalva quanto ao fato de que o discurso psicanalítico em sua essência, com relação a esses psiquiatras, ditos como precursores, não é considerado um discurso psicanalítico. Naquele momento havia um direcionamento segundo o qual a psicanálise oferecia como alternativa uma teoria moderna e científica para preceitos da moral tradicional, até então vistos como arcaicos e ultrapassados.

Assim, o discurso psiquiátrico e psicanalítico no Brasil no início do século XX era marcado pela tentativa de conciliação de vários pontos de vista: a noção de doença mental e o comportamento do homem em geral. A colaboração dos médicos Juliano Moreira e Afrânio Peixoto na divulgação (e colaboração) da teoria de Emil Kraepelin, que defendia uma psiquiatria organicista, também contribuiu com a divulgação e a difusão da psicanálise (MENESES apud BARROS, 2010).

Arthur Ramos, no período em que viveu na Bahia, vinculou-se à psicanálise defendendo e divulgando tais teorias, publicando artigos sobre vários temas psicanalíticos e reunindo em torno de si um grupo que estudava a psicanálise. Ao acompanhar a trajetória de Arthur Ramos, observamos que a psicanálise servirá de instrumento a ser utilizada em vários campos de trabalho: na compreensão da loucura, da educação infantil e da cultura negra e, além disso, na descrição dos meios institucionais e na divulgação de seus trabalhos para a comunidade médica, em particular a dos psiquiatras baianos.

De outra feita, a psiquiatria no Brasil remonta os primórdios do século XX e apresentava como principal referência a teoria organicista de um representante da escola alemã, Emil Kraepelin, que se opunha à escola francesa, calcada numa concepção moral da doença mental e enormemente difundida no Brasil. Nesse sentido, ao buscar identificar uma lesão cerebral ou uma etiologia baseada no paradigma bacteriológico que vinha dominando a psiquiatria nesse período, a miscigenação e a degenerescência também compunham as ideias dos psiquiatras brasileiros, que se aliaram à escola alemã.

Nesse aspecto, o médico brasileiro Raimundo Nina Rodrigues (1862-1906), em seu artigo La paranoia chez les négres (publicado em 1903 na revista francesa Archives d' Anthropologie Criminele, de Criminologie et de Psychologie Normale et Pathologique, de Lyon), marca uma longa influência na classe médica da época. Seu artigo versa sobre o conceito de paranoia e suas possíveis formas clínicas 
associadas aos atos violentos e criminosos, dentre os quais se destacam, de maneira ilustrativa, inúmeros casos clínicos usados na discussão da semiologia sobre a paranoia nos negros e mestiços brasileiros (ODA; DALGALARRONDO, 2004). Raimundo Nina Rodrigues criou uma escola com larga influência na psiquiatria brasileira e na difusão de suas ideias e teve em Arthur Ramos seu representante mais fiel, que, por sua vez, divergiu de Nina Rodrigues e desenvolveu outra abordagem na compreensão da paranoia do Negro no Brasil. O médico Nina Rodrigues intentava demonstrar que a paranoia que incidia sobre os negros, em sua essência, suas manifestações, não diferia daquela vista nos brancos.

Nina Rodrigues divergia enfaticamente das ideias dominantes dos psiquiatras brasileiros que negavam ao conjunto de indivíduos de ascendência africana a capacidade cerebral ou o grau de desenvolvimento mental necessários para que apresentassem sintomas mais complexos, como a sistematização dos delírios e as manifestações clássicas da histeria. A influência de várias escolas psiquiátricas implicava em observações de perturbações mentais em não europeus, em raças primitivas e selvagens, ou em povos não civilizados, nos assim chamados estudos de psicopatologia, ou melhor, a psiquiatria comparada. Destaca-se o relevante papel de Nina Rodrigues no cenário brasileiro e a consequência de sua posição multirracial, em particular do Negro, o que implicou no fato de Arthur Ramos também ser um estudioso dessa escola e seguir o que considerou relevante de toda a obra de Nina Rodrigues. No período de 1870 a 1930 estabeleceu-se no Brasil uma larga produção intelectual e científica em que as questões raciais e sociais foram largamente debatidas, visto que faziam coro a uma ideia da identidade nacional.

Não podemos deixar de apontar que, após a Abolição da escravatura em 1888, os entraves, os problemas, as queixas ou tudo o que fosse possível era direcionado aos negros e mestiços brasileiros. E, para dar suporte a essa ideia, evocava-se a ciência. Assim, a teoria da degenerescência e dos determinismos climático, racial e moral podiam responder a vários entraves, aos quais se agregava a miscigenação, ditando a ordem de fatores previamente determinados no crime e na punição. Os pensadores e cientistas brasileiros viramse obrigados a refletir sobre o futuro de um país mestiço num clima tropical. Ou seja, em tese, duplamente fadado ao insucesso, o Brasil ainda não encontrou de 
fato as suas condições da tristeza:

[...] numa terra radiosa vive um povo triste. Legaram-lhe essa melancolia os descobridores que a revelaram ao mundo e a povoaram. O esplêndido dinamismo dessa gente rude que obedecia a dois grandes impulsos que dominavam toda a psicologia da descoberta e nunca foram geradores de alegria: a ambição do ouro e a sensualidade livre e infrene que, como culto, a Renascença ressuscitara (PRADO, 2011, p. 53).

No contraponto desse cenário, Arthur Ramos se afastou da escola de Nina Rodrigues e, influenciado pelo estudo e pela pesquisa da psicanálise, construiu suas análises a respeito da paranoia do Negro no Brasil. Suas pesquisas consideravam, de forma comparativa, o comportamento paranoico com o do homem primitivo, a partir do conceito de regressão. Suas convicções baseavam-se no fato de que haveria a construção paranoica independentemente se homem primitivo ou não. Seguindo o conceito da época, Ramos (1926, p.19), em sua tese, apontava a seguinte expressão: "O selvagem dormita na alma de todo homem, vive à espreita de uma oportunidade para se entremostrar em seus caracteres bárbaros e antissociais, e com isso seria possível pensar na elaboração do conceito de inconsciente folclórico".

Esse apontamento faz jus a uma síntese das teorias de Freud, em particular seu artigo Totem e Tabu ([1912-1913] 2012); além dos conceitos de inconsciente de Carl Jung; de inconsciente intrapsíquico de Janet e Tarde; e não das influências da teoria do atavismo psíquico de Tanzi e Riva. Ramos pretendia formular o inconsciente folclórico e estabelecer uma interlocução freudiana, contida no texto Totem e Tabu, no qual haveria referências ao modo de transmissão das experiências ancestrais na transmissão de uma geração para outra.

A psicanálise possuía em seus conceitos razões para Arthur Ramos construir uma nova nomenclatura a respeito do Negro e das relações sociais, nas quais se apregoava uma forma imperativa da análise do crime e da punição. Ao se utilizar da psicanálise para sua formulação de análise das condições do Negro e das interrelações pertinentes ao crime e à punição, por sua vez, servira ao propósito da década de 1920, em que o programa de higiene mental defendido pela elite da psiquiatria acentuava sua intervenção na prevenção da doença mental das pessoas ditas normais e assim se valia do meio educacional, profissional e social como lugares privilegiados para esse fim. Portanto, o papel do super-Eu, enquanto agente repressor dos impulsos antissociais, consistia em domesticar os instintos 
permitindo o convívio social. Arthur Ramos entendia que a psicanálise poderia ser aplicada na educação como instrumento de investigação dos processos inconscientes que poderiam interferir na formação da criança (BARROS, 2010).

Assim, ao desdobrar a psicanálise em antropologia, entre os anos 1920 e 1940, Arthur Ramos teve na ciência a busca para compreender um contingente de sujeitos, que a partir daí estará à mercê de uma ciência ou de uma moralidade em que cor, raça, moral e atributos físicos ditariam uma análise prévia de persecutoriedade no crime e na punição. Seu nome e o de Roger Bastide figuraram no ápice da produção da antropologia, igualmente influenciados pela literatura psicanalítica, porém com grandes contrastes em outros aspectos. Os autores antropólogo-psicanalíticos buscavam compreender como se organizava culturalmente o pensamento das camadas subalternas da sociedade brasileira, tendo como base uma característica genuinamente arcaica e primitiva, mesmo que os aspectos relativizassem, até certo ponto, as implicações evolucionistas lineares dessa caracterização. Dessa maneira, nos debates da época, se atribuía de forma inconteste o atraso do Brasil ao peso da raça Negra ou à sua herança (BARROS, 2010).

A década de 1930 representou, para o nosso autor, uma virada nos anais da antropologia, visto que fez desse saber o viés de análise do Negro no Brasil e as consequências desdobradas no que tange ao estigma: pobre, psicótico e preto. Sua publicação em 1934 do livro O negro brasileiro apresenta uma vasta pesquisa do Negro e sua cultura singular, que enfatiza o folclore (a razão de pensar o inconsciente folclórico), resultando em O folclore negro do Brasil (1935) e em As culturas negras do Novo Mundo (1936).

Sua aliança com a psicanálise e com as ideias de Lévy-Brühl favoreceram a interpretação dos mitos africanos, da música, da dança e do fenômeno da possessão, fato relevante em sua análise do Negro no Brasil ao consignar ao sujeito, seja ele branco ou Negro, sua dignidade de um sujeito do desejo e consequentemente de sua cultura e singularidade, posto que no momento de sua prática, o Negro estava sob o olhar da ciência médica psiquiátrica, com suas determinações e obscurantismo, para a qual a raça, a degenerescência, a moral e a hereditariedade civilizatória impunham às "sociedades primitivas" o julgo de conceitos pré-determinados de loucura, crime e degeneração. 
A teoria evolucionista social era otimista em relação à possibilidade de um povo tornar-se civilizado (BARROS, 2010), porém, na análise de Arthur Ramos, essa miragem apresentava-se sob outra ordem: procurar na religiosidade dos negros determinantes explicativos das manifestações psicológicas - ao comentar uma afirmação de Raimundo Nina Rodrigues de que a catequese junto aos negros não passou de uma mera ilusão -, visto que eles aceitaram o catolicismo e suas práticas por causa de uma incapacidade psicológica de abstração, incorporando ao seu sistema a relação mítico-religiosa.

Se a incapacidade psicológica de abstração está vinculada a um conceito psicológico e sociológico, trata-se da função da mentalidade primitiva, caracterizada pelo pensamento simbólico, percepção mística e representações coletivas. Portanto, Ramos destaca que os mesmos tipos antropológicos brancos possuem uma mentalidade primitiva (como a criança e o selvagem) e o adulto civilizado apresenta um tipo de mentalidade pré-lógica em certas ocasiões, como os sonhos, a arte etc. Seja pela via da psicanálise (sua referência) ou da teoria de Lucien Lévy-Brühl (que o respaldará no entendimento da mentalidade primitiva), a mentalidade primitiva estaria submetida a um princípio oposto à contradição, sendo denominada como pré-lógica.

Nesse sentido, Ramos advertiu de que a mentalidade pré-lógica não deve ser entendida como anterioridade no tempo, mas uma lógica diferente que se abstém da contradição (BARROS, 2010). Em 1937, ao abandonar a teoria psicanalítica na tentativa da interpretação da cultura negra, sua mirada recaiu sobre o caráter social na inclusão do laço social do Negro e suas inter-relações entre o crime e a punição. Com seu livro Introdução à Psicologia Social (1935), o marco de sua passagem da psiquiatria à antropologia, Ramos demonstra o seu interesse em formatar na psicologia social as relações implicadoras culturais do Negro e sua relação com a noção do primitivo e da loucura.

Assim, fazia coro ao que defendeu em sua tese, construída ao longo da carreira na qual como médico e pesquisador buscou o reconhecimento, na psicanálise, de uma teoria que concebesse um substrato comum - o inconsciente e suas formas de manifestação - ao comportamento da criança, do louco e homem primitivo. Ao lançar o inconsciente folclórico como medida de um entendimento das condições nacionais brasileiras da miscigenação da qual 
somos, desde sempre, constituídos, deve-se considerar a condição de uma paranoização na qual o Negro e todas as condições sociais marginalizadas loucos, homossexuais, mulheres etc. - fizeram (e fazem), na contemporaneidade, parte de instâncias de pré-julgamento: degenerados, miscigenados, imorais e presos à hereditariedade, o mal começa e não acaba para um grupo social, colocado do lado de fora das condições nas quais a burguesia se vê à mercê e ameaçada, isto é, tem de ficar fora essa gente diferenciada.

\section{Neusa Santos Souza: o processo da Identificação do Negro na visão lacaniana}

Uma das formas de exercer autonomia é possuir um discurso sobre si mesmo. Discurso que se faz muito mais significativo quando mais fundamentado no conhecimento concreto da realidade. (SOUZA, 1983, p.17).

As contribuições de Neusa Santos Souza na configuração do processo da Identificação do Negro em particular no Brasil é fruto de sua jornada como mulher Negra, médica psiquiatra e psicanalista do campo lacaniano. Neusa Santos Souza nasceu na Bahia, em Cachoeira, Recôncavo Baiano, no ano de 1948. De formação médica pela FMUFB, no Rio de Janeiro em 1975 defendeu sua dissertação de mestrado: Tornar-se Negro, sob a orientação de José Otávio de Freitas Junior e coorientação de Gregório Baremblitt.

É na direção de seu livro Tonar-se Negro que articularemos o processo da Identificação do Negro no Brasil, pela via do campo lacaniano e sua topologia clínica. Diferentemente do que propôs Arthur Ramos na tentativa de compreensão da singularidade do Negro, na concepção da etnia e as condições antropológicas que configuravam as relações entre negros e brancos, sua proposta de um inconsciente Folklórico repleto de signos condiz em sua análise ao que de mais rico e significativo pudesse elevar o Negro na condição de sujeito do desejo.

Na perspectiva em curso, o estudo sobre as adversidades do Negro no Brasil (inserido e com pretensões sociais) determina uma reflexão a respeito da violência como problema central das relações do Negro com o branco. Ser Negro é ser e sofrer violência de forma constante e cruel, sem pausa e repouso, em uma dupla injunção: a encarar o corpo e os Ideais do Eu do sujeito branco; e a recusar, negar, 
anular a presença do corpo negro.

Note-se que o Ideal do Eu não se confunde com o Eu Ideal: o Eu Ideal é a instância regida pela onipotência, marcada pelo registro do imaginário, caracterizado pelo predomínio das representações fantasmáticas; de outra feita o Ideal do Eu é o domínio do simbólico, articulação e vínculo no simbólico, ou seja, registro que determina a Ordem simbólica e a Lei que de certa maneira fundamenta esta ordem.

O Ideal do Eu é a instância que estrutura o sujeito psíquico vinculando-o à Lei, à Ordem e ao lugar do discurso, articulante libidinal estrutural do sujeito e seu lugar na cultura. Nessa perspectiva, o Negro no Brasil estaria em qual posição? O Negro que estamos levando em consideração é aquele cujo Ideal do Eu é branco. O Negro estaria imerso numa ideologia imposta pelo branco como ideal a ser atingido, o que faz endossar a luta para esse fim. Afinal, como se constrói o Ideal do Eu do Negro no Brasil? De acordo com Souza (1984), é fundamental traçarmos uma problemática que contemple, acolha e aprofunde os impasses do processo da identificação do Negro no Brasil e sua relação com os fatores da paranoia social.

Podemos analisar, na perspectiva de Neusa Santos Souza, o que falta ao Negro no Brasil para se tornar Negro e quais fatores implícitos e explícitos atravessam sua condição de sujeito do inconsciente e do laço social. Em primeira instância a análise se configura prefaciando os comentários de Jurandir Costa Freire sobre as relações entre o Ideal do Eu do Negro e do branco e afirma que o Ideal do Negro é forjado no desrespeito àquilo que na linguagem psicanalítica denominamos Identificações normativas ou estruturantes.

De outro modo, mesmo considerando um jogo de reciprocidade no qual os três registros - o simbólico, o imaginário e o real - não poderiam ficar de fora para quem da técnica psicanalítica faça uso, muitas dificuldades se justificam e se esclarecem quando se faz essas distinções. Nessa trilha, veremos como no seminário os escritos técnicos de Freud Lacan ([1953-1954]1986) trabalha a tópica do imaginário. Também em Situação da psicanálise e formação do psicanalista, em 1956, Lacan (1998) chama atenção para o fato de Freud ter levado em conta o imaginário como não ilusório, e que está subordinado à determinação simbólica.

O imaginário, junto com o simbólico e o real, é uma das dimensões do 
espaço. A ordem do imaginário é "constituída pelas imagens e pela libido, elemento sexual, vital, que, partindo do corpo como fonte, circula entre as imagens - Eu e imagem do Eu - ao tempo em que Ihes dá sua necessária sustentação" (SOUZA, 1991, p. 33). Nesse traçado, Lacan tem a articulação do imaginário no campo da teoria do narcisismo. Em À Guisa de Introdução ao Narcisismo (1914), Freud o conceitua como um complemento libidinal presente em todos os sujeitos, um narcisismo primário tendo no corpo a sede própria das pulsões que têm em mira sua satisfação. Essa satisfação pelo autoerotismo é essencial para a formação do Eu; trata-se de uma nova ação psíquica que viria a ordenar e substituir o caos das pulsões parciais por uma imagem unitária, fonte de todo o erotismo como sentimento de si mesmo. Esse enigma proposto, mas não desvelado, essa nova ação psíquica estruturante do narcisismo, foi palco de análise por Lacan, formalizada no estádio do espelho, uma teoria da organização imaginária do sujeito, teoria da formação do Eu4 4 Seguimos, então, Lacan ([19531954] 1986) no que se refere à tópica do imaginário:

É a aventura original através da qual, pela primeira vez, o homem passa pela experiência de que se vê, se reflete e se concebe como outro que não ele mesmo - dimensão essencial do humano, que estrutura toda a sua vida de fantasia. Supomos na origem todos os Issos, objetos, instintos, desejos, tendências etc. É, pois, a pura e simples realidade que não se delimita em nada, que não pode ser ainda objeto de nenhuma definição, que não é nem pode ser ainda objeto de nenhuma definição, que não é nem boa, nem má, mas ao mesmo tempo caótica e absoluta original. É o nível ao qual Freud se refere em Die Verneinung, quando fala dos julgamentos de existência - ou bem é, ou bem não é. É aí que a imagem do corpo dá ao sujeito a primeira é forma eu lhe permito situar o que é e o que não é seu. Bem, digamos que a imagem do corpo, se a situamos no nosso esquema, é como o vaso imaginário que contém o buque de flores real. Aí está como nós podemos representar o sujeito anterior ao nascimento do eu, e o surgimento deste. (LACAN, [1953-1954] 1986, p. 96).

Diante dessa perspectiva podemos levar, nas palavras de Neusa Santos Souza, a proposta de Tornar-se Negro na construção de um processo de Identificação singular em que o Outro requer ser implicado na percepção dialética, seja negro ou branco. Conforme as expressões de Fanon (1966), o Negro tem duas dimensões, uma com seu semelhante e outra com o branco, um mesmo Negro se comporta de modo diferente com um Negro ou com um branco. Sua

\footnotetext{
${ }^{4}$ Nos seus Escritos, em O estádio do espelho como formador do eu ([1949] 1998), Lacan fala da identificação do sujeito com uma imagem e retoma a expressão narcisismo primário como o investimento libidinal próprio a esse momento.
} 
relação estabelece um estado, como responder a um e a outro na contemporaneidade, visto que no Brasil o Racismo é Estrutural.

\section{Frantz Fanon: as articulações entre o colonizado, o colonizador e a subjetividade}

O que se articula entre o colonizador e o colonizado no Brasil pela via da escravatura tem resultados até a contemporaneidade, visto que pagamos o ônus trágico de um racismo estrutural que subverte no sujeito do inconsciente (na expressão de Lacan) sua capacidade subjetiva de uma identificação singular perante seu semelhante. Assim, ao pensar na relação estabelecida por Fanon entre o colonizador e o colonizado em que a tragédia se estabelece no processo de alienação, nossa proposta se identifica com a afirmação de que as chamadas patologias sociais (SAFATLE, 2018), em que há o desarranjo de um estado persecutório tanto do Negro quanto do branco pelo viés do racismo, dão advento a uma paranoia de violência e crime.

Contextualizamos com um recorte do relato de Fanon a respeito de uma guerra antiga que pouco difere (a ser pelos protagonistas) de nossa situação atual, pois são as condições de um estado em que a Necropolítica impera no esvaziamento da subjetividade do sujeito e de sua alteridade.

O Colonialismo e os efeitos das perturbações mentais abordados por Frantz Fanon são descritos no relato de sua experiência clínica psiquiátrica mediante a guerra na Argélia. Trata-se de uma experiência traumática, como expressa Fanon (1968, p.211): "e teremos de tratar por anos ainda as feridas múltiplas e às vezes indeléveis deixadas em nossos povos pela derrota colonialista".

A proposta de Fanon traz em sua extensão o sofrimento psíquico causado pelo racismo e pela presença viva da loucura no sistema colonial. Nesse sentido, poderíamos indagar em que dimensão essa abordagem se faz presente em seus escritos. Com efeito, a situação colonial e o racismo visam primeiramente abolir toda a separação entre o Eu interior e o olhar exterior. Trata-se de anestesiar os sentidos e de transformar o corpo do colonizado em coisa, cuja rigidez lembra a de um cadáver. À anestesia dos sentidos junta-se a redução da vida em si mesma ao desprovimento extremo da carência. 
Fanon não pensa o colonialismo somente em África no processo de sua descolonização, mas também em outros países (por exemplo a colonização portuguesa em Guiné-Bissau, Angola, Zimbábue e Moçambique), mas a temática campesina terá eco na África do Sul, com a abordagem de efeitos e desdobramentos indiretos em Os condenados da terra.

Na perspectiva sociohistórica, o impacto da globalização e de certo modo da circulação das concepções essenciais da identidade pode ser o causador dessa proposição:

[...] os processos de identificação são cada vez mais aprendidos não a partir de uma perspectiva ontológica, mas de um ponto de vista de um sujeito face ao seu desejo. Manifesta-se por toda parte um interesse renovado pela análise das relações do sujeito, da linguagem e da representação. 0 cepticismo face uma postura da razão transcendental ganha em intensidade. É concedida uma importância nova, a heterogeneidade das temporalidades e a reflexão sobre a natureza democrática, as condições do viver-em-conjunto e aos modos de relação com o Outro e com o mundo. (MBEMBE, 2000, p. 8).

O sujeito da linguagem e da representação, como se diz ou se expressa, podemos simplificar como o sujeito do inconsciente. Assim, o sujeito da linguagem na sua relação com o Outro é condição implícita na forja da constituição identitária do sujeito. Para Fanon, esse conceito é de relevância nas relações entre o colonizador e o colonizado, pois, por ser uma negação sistematizada do Outro, uma decisão furiosa de recusar ao Outro qualquer atributo de humanidade, o colonialismo compele o povo dominado a se interrogar constantemente: Quem sou Eu na Realidade?

Essa indagação identitária e ao mesmo tempo da negação do Outro subverte o laço social e subverte a condição proposta do Ideal do Eu, isto é, do domínio do simbólico para que o sujeito sobreviva no desejo e na relação com o Outro. De certa maneira, o colonizado não seria capaz de constituir-se na identidade e, assim, estaria fadado a ser ninguém.

Na expressão de Neusa Souza, o processo de tornar-se Negro implica na sua identidade como fundamental:

O Ideal do Eu é do domínio do simbólico. Simbólico quer dizer articulação e vínculo. Simbólico é o registro ao qual pertencem a Ordem simbólica e a Lei que funda esta ordem. O Ideal do Eu é, portanto, a instância que estrutura o sujeito psíquico, vinculando-o à Lei e à Ordem. É o lugar do discurso. O Ideal do Eu é a estrutura mediante a qual se produz a conexão da normatividade libidinal com a cultura. (SOUZA, 1990, p.33). 
Podemos indagar o seguinte: E o Negro? O Negro de que estamos falando é aquele cujo Ideal do Eu é branco. Nessa análise, pela via de Fanon, a identificação é com o colonizador, pois o Negro que ora tematizamos é aquele que nasce e sobrevive numa mesma ideologia imposta pelo branco como ideal a ser atingido e que endossa a luta para realizar este modelo. Por conseguinte, cabe questionar: como se constrói o ldeal do Eu desse Negro?

De certa maneira, esse dispositivo ou modelo seria pela via de construção de um Ideal do Eu branco, sendo a primeira regra básica e primordial a se impor ao Negro pela negação o expurgo de qualquer mancha negra. A rejeição, levada no patamar do desprezo e do desespero, violenta o corpo físico. Para Fanon (1968, p. 212), "a condição na qual se encontra o povo argelino na guerra de libertação nacional, tornou-se um terreno favorável em manifestações de transtornos mentais". Sua análise se baseia no que a psiquiatria clínica apresenta sob a rubrica de *Psicose Reacional. Esta ênfase clínica psiquiátrica leva em consideração o acontecimento que desencadeou a doença e a história psicológica, afetiva e biológica do paciente e do meio. Dos casos relatados, fica explícita a atmosfera sangrenta e cruel, a generalização de práticas desumanas e a impressão pertinaz que têm os indivíduos de assistirem a um verdadeiro apocalipse.

A condição do processo de colonização se instala não somente pelo uso da imposição e violência, mas também, conforme salienta Fanon, como fornecedora de hospitais psiquiátricos e sua dificuldade de curar ou lidar com as anormalidades que se impuseram nessa ocasião (1954) em que o meio social sofria um tipo de colonização. Os casos clínicos relatados por Fanon (2005) são o mais fiel retrato do sofrimento que o colonialismo produziu.

Dj..., ex-estudante, soldado da E.L.N., 19 anos. Quando chega ao Centro, sua doença já tem vários meses. A aparência é característica: sumamente deprimido, lábios secos, mãos permanentemente úmidas. Suspiros incessantes agitam-Ihe o peito. Insônia pertinaz. Duas tentativas de suicídio desde o início das perturbações. Enquanto conversa, adota atitudes de escuta alucinatória. Por vezes o olhar fixa-se durante alguns instantes num ponto do espaço, enquanto o rosto se anima, dando ao observador a impressão de que o doente assiste a um espetáculo. Pensamentos pouco nítidos. Alguns fenômenos conhecidos em psiquiatria sob o nome de barragem; um gesto ou uma frase esboçada são bruscamente interrompidos sem motivo aparente. Mas, sobretudo, um elemento em particular chama a nossa atenção: o doente fala de seu sangue derramado, de suas artérias que se esvaziam, de seu coração que para de funcionar... libertação. Passados vários meses, recebi notícias de casa. 
Soube que minha mãe tinha sido morta à queima-roupa por um soldado francês e que duas de minhas irmãs tinham sido levadas pelos militares. Até hoje não sei o que foi feito delas. Fiquei terrivelmente abalado com a morte de minha mãe. Tendo meu pai morrido há muitos anos, era eu o único homem da família, minha única ambição foi sempre atingir uma posição qualquer que me permitisse melhorar a existência de minha mãe e de minhas irmãs. Um dia, fomos a uma propriedade de colonos onde o administrador, ativo colonialista, já liquidara dois civis argelinos. Chegamos à casa dele de noite. Mas ele não estava lá. Em casa só estava sua mulher. Logo que nos viu, ela se pôs a suplicar que não a matássemos: 'Eu sei que vocês vieram em busca do meu marido' disse ela, 'mas ele não está aqui. Quantas vezes disse a ele que não se metesse em política!'. Foi decidido que aguardaríamos a volta do marido. Mas eu fitava a mulher e pensava em minha mãe. A mulher, sentada numa poltrona, parecia ausente. Eu me perguntava por que a gente não a matava. E em dado momento. ela percebeu que eu a observava. Então atirou-se sobre mim, gritando: 'Eu lhe suplico... não me mate... Tenho filhas'. Um instante depois ela estava morta. Matei-a com minha faca. O chefe me desarmou e deu ordem de partirmos. Alguns dias mais tarde fui interrogado pelo chefe do setor. Imaginei que ia ser condenado à morte, mas não me incomodei. (1) Daí por diante passei a vomitar depois das refeições e dormir mal. Agora, todas as noites, essa mulher vem reclamar meu sangue. E o sangue de minha mãe, onde está?". À noite, logo que o doente se deita, o quarto "fica cheio de mulheres", todas iguais. É uma reedição em múltiplos exemplares de uma única mulher. Todas têm um buraco aberto no ventre. Estão exangues, pálidas e assombrosamente magras. Essas mulheres atormentam o jovem enfermo e exigem que ele thes restitua o sangue derramado. Nesse momento, um rumor de água corrente enche o quarto, amplia-se até evocar a estrondo de uma cachoeira, e o doente vê o soalho a embeber-se de sangue, seu sangue, enquanto as mulheres se tornam cada vez mais rosadas e a ferida começa a fechar-se. Banhado de suor e tremendamente angustiado, o enfermo desperta e permanece agitado até ao amanhecer. (FANON, 2005, p. 216-220).

A incidência de forma subliminar ou direta pela via da Necropolítica no passado e na contemporaneidade pela violência e crime no racismo estrutural e colonialista implica em uma identificação das diferenças entre o Negro e o branco. A expressão usada por ARENDT (2007) a "banalidade do mal" pode traduzir muito bem nosso intento nesse trabalho: por uma causa, sem causa, mas um mal causado pela ignorância deu uma causa sem razão.

\section{Conclusão}

As implicações da visão psicanalítica do processo da identificação do Negro no Brasil em sua singularidade com relação ao seu semelhante (proposta em primeiro lugar pela escrita freudiana e depois por Lacan no conceito do Estádio do Espelho) marcam, na percepção deste estudo acerca do Negro no Brasil, a sua relação com o branco e o processo da identificação, abordado por Arthur Ramos 
e Neusa Santos Souza, que formaliza de maneira singular as relações fundamentais da identificação pela via do estádio do espelho na composição entre o Negro e o branco, forjando um corpo desalinhado de seu Ideal do Eu.

Já as articulações de Fanon corroboram nosso intuito oferecendo um recorte de vivência em que a violência e o crime justificável impactam em trauma e sofrimento, o que pode ser relacionado ao cenário do cotidiano testemunhal da contemporaneidade brasileira das comunidades em que o Negro é visto como um sujeito suspeito de tudo: no centro urbano está limitado a uma zona restrita de circulação, moradia e lazer, fora disso está na zona de perigo; a patologia social de uma paranoia se manifesta e logo carrega o estigma de perigoso, violento, assassino e marginal.

Nossa sociedade encontra-se sob as condições de uma vertente na qual o racismo estrutural corresponde à Necropolítica (MBEMBE, 2018). Na visão de Fanon, a ocupação colonial implica, acima de tudo, uma divisão do espaço em compartimentos, com a definição de limites e fronteiras internas representadas por quartéis e delegacias de polícia, sendo reguladas pela linguagem da força pura imediata e pela ação direta e frequente; baseando-se no princípio da exclusividade recíproca: o mais importante é o modo como o poder de morte opera.

Por outro lado, a ocupação colonial tardia difere muito da primeira ocupação moderna, em sua combinação entre disciplina, biopolítica e necropolítica. Fanon apresenta uma das formas bem-sucedidas dessa lógica ao analisar a Faixa de Gaza, bem como podemos fazer uma leitura de nosso território, visto que o Negro no Brasil e sua Identificação estão alijados do Laço Social e seu reconhecimento ainda demora a chegar.

\section{Referências}

ARENDT H. Eichmann em Jerusalém, um relato sobre a banalidade do mal. São Paulo, Cia das Letras, 2007.

COSTA, J. F. apud SOUZA S. N. Tornar-se Negro ou As vicissitudes da Identidade do Negro Brasileiro em Ascensão Social. Rio de Janeiro: Graal, 1983.

COSTA, J. F. História da Psiquiatria no Brasil - um corte ideológico. Rio de Janeiro: Xenon, 1989. 
COSTA, J. F. Violência e Psicanálise. Rio de Janeiro: Graal, 1984.

CÉSAIRE, A. Discurso sobre o colonialismo. São Paulo: Veneta, 2020.

FOUCAULT, Michel. História da loucura na Idade Clássica. Trad. Maria Thereza Albuquerque e J.A. Guilhon Albuquerque. São Paulo: Perspectiva, 1972.

FANON, F. Os condenados da terra. Juiz de Fora: UFJF, 1968.

FANON, F. Pele negra máscaras brancas. Bahia: Editora da UDUFB, 2008.

FANON, F. ESCUCHA, blanco!. Barcelona, Madri: Nova Terra, 1966.

FREUD, S. Esboço para a "Comunicação Preliminar" de /Carta a Josef Brever. In: FREUD, S. Obras Psicológicas Completas de Sigmund Freud, v. I. Rio de Janeiro: Imago, 1893/2006.

FREUD, S. Totem e Tabu. In: FREUD, S. Obras Psicológicas Completas. Trad. Órizon Carneiro Muniz, v. XIII. Rio de Janeiro: Imago, 1913/1996.

FREUD, S. Introdução ao Narcisismo. In: FREUD, S. Obras Completas, v. 12. Trad. Paulo César de Souza. São Paulo: Companhia das Letras, 1914/2010.

GRECCO, J. E. A foraclusão do Nome-do-Pai e as dificuldades do psicótico no laço social: de um tratamento possível da Psicose. São Paulo: Pontifícia Universidade Católica de São Paulo, Tese de Doutorado, 2015.

LACAN, J. (1949/1998). O estádio do espelho como formador da função do eu tal como nos é revelada na experiência psicanalítica. In: LACAN, Jacques. Escritos. Trad. Vera Ribeiro. Rio de Janeiro: Jorge Zahar.

LACAN, J. Função e Campo da fala e da linguagem. In: LACAN, Jacques. Escritos. Trad. Vera Ribeiro. Rio de Janeiro: Jorge Zahar, 1953/1998.

LACAN, J. Resposta ao comentário de Jean Hyppolite. In: LACAN, Jacques. Escritos Trad. Vera Ribeiro. Rio de janeiro: Jorge Zahar, 1954/1998.

LACAN, J. O Seminário Livro I: Os escritos técnicos de Freud. Trad. Betty Milan. Rio de Janeiro: Jorge Zahar Editor, 1953-1954/1986.

MBEMBE, A. Necropolítica. São Paulo: N-1 edições, 2018.

MBEMBE, A. A universalidade de Franz Fanon. Disponível em: http://artafrica.letras.ulisboa.pt/uploads/docs/2016/04/18/5714de04d0924.pdf.

RAMOS, A. Loucura e Crime - questões de psychiatria medicina forense e psychologia social. Porto Alegre: Edição da Livraria do Globo, 1937.

RAMOS, A. O negro na civilização brasileira. Rio de Janeiro: Editora da Casa do Estudante do Brasil, 1971.

RAMOS, A. Arquivos de Arthur Ramos - Inventario Analítico. Rio de Janeiro: Edições Biblioteca Nacional, 2004.

RODRIGUES, R. N. A paranoia nos negros: estudo clínico e médico-legal. Revista Latino-americana de Psicopatologia Fundamental, São Paulo, ano VII, n. 2, 161-178, jun./ 1903/2004.

RODRIGUES, R. N. As anormalidades coletivas. Brasília, DF: Edições do Senado 
Federal, 2006.

PRADO, P. Retrato do Brasil. São Paulo: Editora Companhia das Letras, 1996.

PEREIRA, M. Pânico e Desamparo. São Paulo: Escuta, 2008.

SAFATLE, V. O circuito dos afetos. Copos políticos, desamparo e o fim do indivíduo. São Paulo: Cosac Naify, 2015.

SAFATLE, V. Patologias do social - arqueologia do sofrimento psíquico. Belo Horizonte, MG: Autêntica, 2018.

SCHWARCZ, M.L.; F. GOMES. Dicionário da Escravidão e Liberdade. São Paulo, Companhia das Letras, 2018.

SOUZA S. N. Tornar-se Negro ou As vicissitudes da Identidade do Negro Brasileiro em Ascensão Social. Rio de Janeiro: Graal, 1983.

SOUZA S. N. A psicose - um estudo lacaniano. Rio de Janeiro: Campus, 1991. 